\title{
Beneficiary Effect of Fibrin Glue on Healing of Ileoileal Anastomoses in Rats
}

\author{
IOANNIS GEROGIANNIS ${ }^{1}$, APOSTOLOS PAPALOIS ${ }^{2}$, DIMITRA PSALLA ${ }^{3}$ and APOSTOLOS KAMBAROUDIS ${ }^{4}$ \\ ${ }^{1}$ Department of Surgery, Kingston Hospital NHS Foundation Trust, London, U.K.; \\ ${ }^{2}$ ELPEN Experimental - Research Center, Athens, Greece; \\ ${ }^{3}$ Laboratory of Pathology, School of Veterinary Medicine, Aristotle University of Thessaloniki, Thessaloniki, Greece; \\ ${ }^{4} 5^{\text {th }}$ Department of Surgery, Hippokrateion University Hospital, Thessaloniki, Greece
}

\begin{abstract}
Background/Aim: Intestinal anastomosis' integrity is crucial in surgery. This study aimed to investigate whether fibrin glue (FG) (a fibrin sealant containing human factor XII and fibrinogen) has a positive effect on the healing and the integrity of the ileoileal anastomosis in rats. Materials and Methods: Twenty Wistar rats underwent enterotomy, ileoileal anastomosis and divided into four groups (A: complete anastomosis-no $F G$, $B$ : complete anastomosis-FG, $C$ : incomplete anastomosis-no $F G$, D: incomplete anastomosis-FG). Data included leak, adhesions, bursting pressure of the anastomosis, neoangiogenesis, and hydroxyproline levels. Results: Angiogenesis was significantly higher in group $B$ compared to group $A$ ( $p=0.019)$. There were no significant differences between groups $A$ and $B$ regarding adhesions, hydroxyproline, and bursting pressure ( $p=0.500, p=0.158$ and $p=0.829$, respectively). Hydroxyproline levels were higher in group $D$ compared to $C$, but did not reach significance ( $p=0.098)$. Conclusion: Fibrin glue has a positive effect on ileoileal anastomoses. It is not entirely clear whether this effect is due to mechanical support or to the facilitation of the healing process or both. Further research is needed before FG can be applied to humans.
\end{abstract}

Small bowel anastomoses, and especially ileoileal ones, are ubiquitously present in every general surgeon's practice. A safe healing of the anastomosis is crucial for the outcome of the operation and the recovery of the patient after a simple

This article is freely accessible online.

Correspondence to: Ioannis N. Gerogiannis, MD, Ph.D., FRCS, FICS, MFSTEd, Department of General and Emergency Surgery, Kingston Hospital NHS Foundation Trust, Galsworthy Road, KT2 7QB, Surrey, U.K. Tel: +44 7429981412, e-mail: ioannis.gerogiannis@nhs.net, drgerogiannis@gmail.com

Key Words: Glue, bowel, ileoileal, anastomosis, hydroxyproline, healing. or a complex abdominal procedure. Ileoileal anastomoses are performed in case of small bowel obstruction and strangulated hernias, trauma, Crohn's disease or reversal of ileostomy. Although anastomosis can be safe when performed on a patient with no comorbidities, the procedure is clean and the surgeon is experienced, some anastomoses continue to leak. Published studies report that the overall morbidity is $22.8 \%$ and mortality $2.5 \%$ (1).

Hence there is an ongoing need to discover innovative solutions to improve the strength of the anastomosis, and reduce the possibility of a leak, other post-operative complications and finally mortality. To achieve this goal, various techniques or materials have been applied. However, only few studies are using fibrin glue (FG) for small bowel anastomoses and the results are inconclusive.

FG is a fibrin sealant containing human factor XII with human fibrinogen. It is used for haemostasis during surgical procedures, when control of bleeding by conventional surgical techniques is ineffective or impractical (as a sealant) and as an adjunct for closure of colostomies and for mesh fixation in repair of abdominal hernias. Mimicking the coagulation process, FG forms an insoluble fibrin clot which appears as a white, elastic mass which firmly adheres to tissue and which can be used to achieve haemostasis or seal tissue sealing $(2,3)$.

In this study, we performed an ileoileal anastomosis on rats using a specific surgical technique and applying FG on the suture line. Our aim was to investigate whether FG can have a positive effect on the healing and the integrity of the anastomosis.

\section{Materials and Methods}

Twenty female Wistar rats with mean body weight of $244 \mathrm{~g}$ were used for our study. The experiments were performed at the animal laboratory of ELPEN's Experimental - Research Center, Athens, Greece. The study protocol was approved by the Research Ethics Committee of the Veterinary Government Department of Attika with Protocol number 20-19.01/2012 and 357-05/02/2013. The study was conducted in accordance with the Declaration of Helsinki. 
The ELPEN Experimental - Research Center provided specialised personnel to facilitate the progress of the experiments and a specialised veterinary surgeon who supervised the experimental process.

The animals were housed to a standard animal facility with a temperature range between $20-26^{\circ} \mathrm{C}, 50-60 \%$ humidity and adequate ventilation with 12/12-hour daylight/darkness. They had free access to pellet type food (Ratti-Topi, Company Vergerio Mangimi s.r.l., Padova, Italy) and water throughout the whole process.

\section{Experimental design.}

Groups. According to the type of the anastomosis and the use of FG the animals were divided into 4 groups. All animals underwent a laparotomy, enterotomy of their ileum and end-to-end handsewn ileoileal anastomosis. Five animals had a complete end to end ileoileal anastomosis with no FG (group A). Five animals had an incomplete end to end ileoileal anastomosis with no FG (group C). Five animals had a complete end to end ileoileal anastomosis and FG was used on the suture line to study its effect on the healing and integrity of the anastomosis, (group B). Five animals had an incomplete end to end ileoileal anastomosis and FG was used on the suture line (group D).

Anaesthesia. Animals were anaesthetised by intramuscular injection of a Ketamine $100 \mathrm{mg} / \mathrm{kg}$ and Xylazine $10 \mathrm{mg} / \mathrm{kg}$ solution. After the induction of anaesthesia and prior to the laparotomy, animals were left for 15 minutes in a quiet and dark environment. An extra anaesthetic dose, equal to the $1 / 3$ of the initial one, administered in case there was a need for more anaesthetic.

Operative procedure. Laparotomy was performed after shaving the abdominal wall and applying antiseptic solution (povidone iodine $10 \%)$. A midline incision was used to enter in the peritoneal cavity. The caecum was identified and then a part of the small bowel was carefully pulled out of the abdomen in order to preserve its vascularity and not traumatise its mesentery. Furthermore, a protective gauze was placed around it to prevent spillage of contents during the enterotomy, which was performed approximately $15 \mathrm{~cm}$ from the ileocaecal junction. Post-enterotomy, the contents from the efferent and the afferent lumen were washed out and an end-to-end handsewn anastomosis was performed with Polypropylene suture 60 in an interrupted full thickness manner.

To avoid a tight anastomosis, a small $8 \mathrm{Fr}$ plastic tube was inserted in both lumens and removed before inserting the last two sutures (Figure 1). The number of the interrupted sutures were between 6 and 8, depending on the diameter of the ileum of each animal. A wash out of the abdominal cavity was performed with normal saline and the anterior abdominal wall was closed in one layer with a continuous Silk 3-0 suture. Povidone Iodine Solution $10 \%$ was applied on the wound.

In the case of incomplete anastomosis, the same procedure was applied except no further sutures were applied after the removal of the plastic tube. In the treatment groups, FG was applied on the suture line in order to fully cover it irrespective of the type of anastomosis (complete or incomplete). We used FG meticulously to prevent spillage of the FG to surrounding tissues and intrabdominal organs (Figure 2).

Post-operative care. At the end of the experiment, the animals were placed in cages with infrared beam and observed for an hour until they recovered completely and had adequate mobilisation. Post

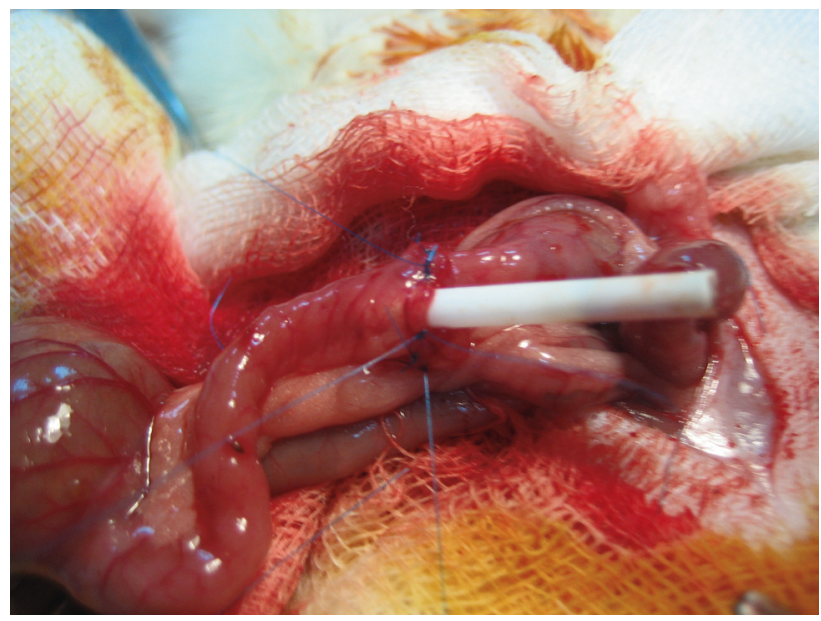

Figure 1. End to end handsewn ileoileal anastomosis with use of plastic catheter $8 \mathrm{Fr}$

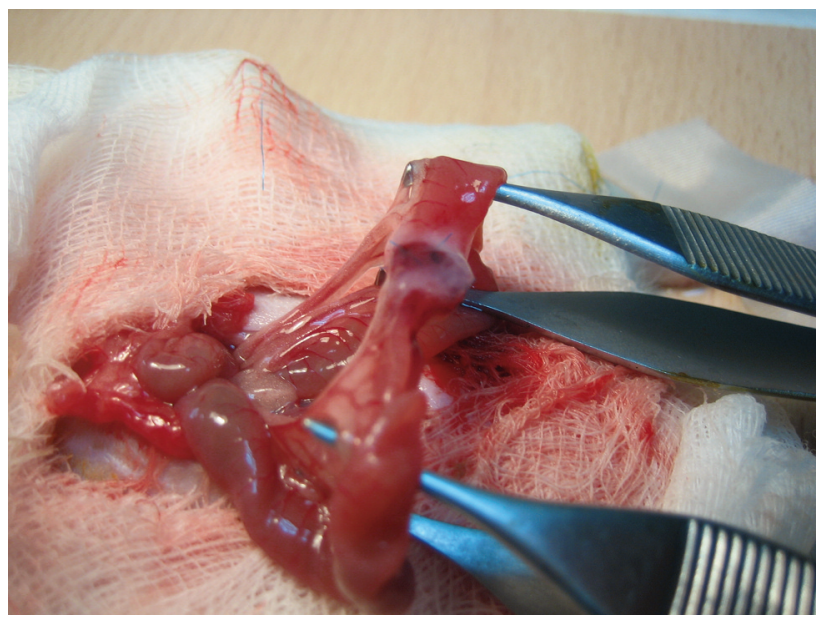

Figure 2. Application of the fibrin glue on the anastomosis.

operatively animals received clear fluids for the first 12 hours and free diet after that. The animals received analgesia and antibiotics for 2 days post-operatively (Carprofen $5 \mathrm{mg} / \mathrm{kg} / 24 \mathrm{~h}$ subcutaneously and Enrofloxacin $10 \mathrm{mg} / \mathrm{kg} / 24 \mathrm{~h}$, respectively).

Sacrifice. Animals were sacrificed on the 7th post-operative day after intramuscular administration of ketamine $100 \mathrm{mg} / \mathrm{kg}$ and xylazine 10 $\mathrm{mg} / \mathrm{kg}$ followed by a high dose of intravenous pentobarbital.

A laparotomy was performed after application of povidone iodine solution $10 \%$ on the previous midline incision and removal of the silk sutures. After entering the peritoneal cavity, an assessment was performed and the findings were recorded (presence of peritonitis, free fluid, pus, reactive fluid or enteral contents, collections or adhesions). 


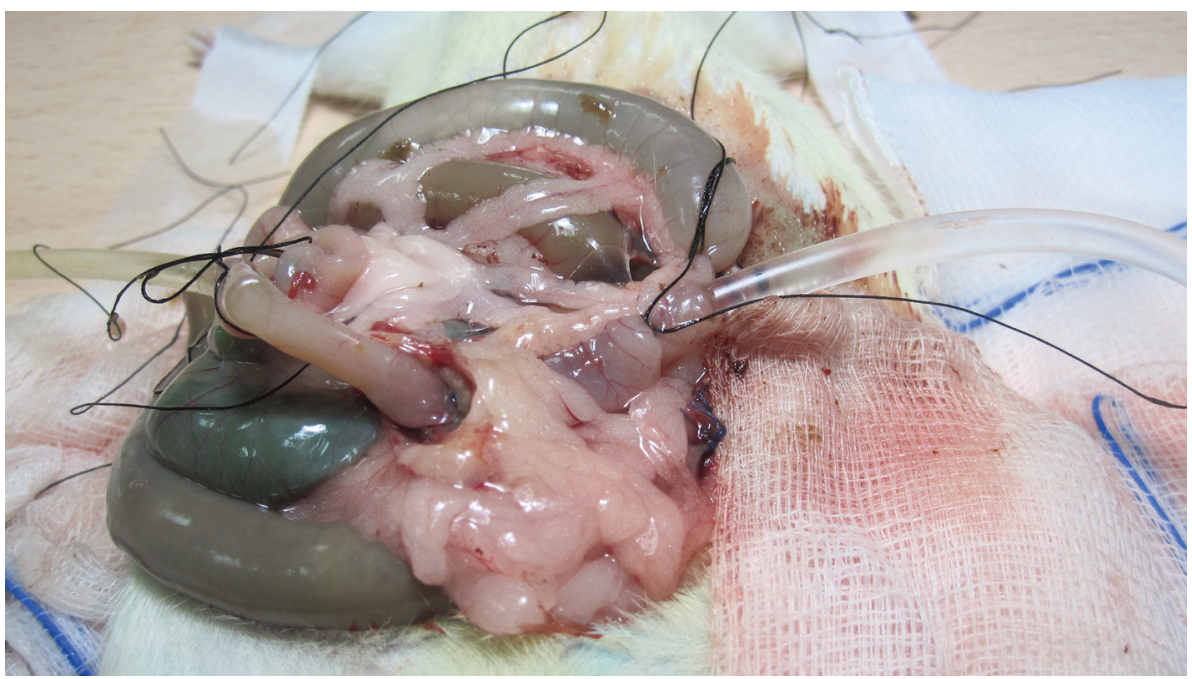

Figure 3. Measurement of bursting pressure of the anastomosis.

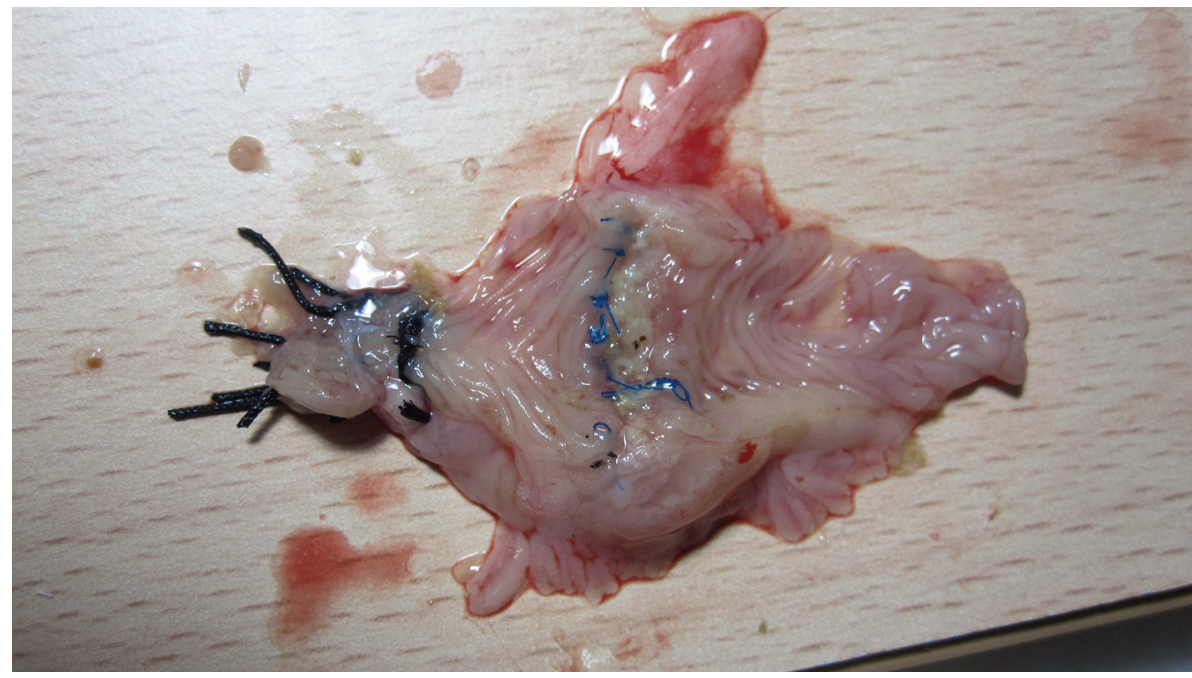

Figure 4. Small bowel specimen with the anastomotic suture line.

Study outcomes. The evaluation of the adhesions was made according to the Van de Ham's scoring system (0: no adhesions; 1: adhesions towards the anastomosis line from the omentum; 2 : adhesions of bowel and omentum towards the anastomosis line; 3 : extensive adhesions towards the anastomosis line and contemporary presence of abscess) (4).

After isolating a part of the ileum measuring $10 \mathrm{~cm}$ including the anastomosis, we performed small bowel resection. A washout of any intraluminal contents was performed in order to clean the bowel. To measure the bursting pressure of the anastomosis, two catheters $14 \mathrm{G}$ were placed and fixed with 3-0 silk on both ends of the bowel segment (Figure 3). On one end a pump containing normal saline was used with a rate of $0.5 \mathrm{ml} / \mathrm{min}$ and the other end was connected with an electronic sensor for continuous monitoring of the intraluminal pressure $(\mathrm{mmHg})$. After the measurements, the anastomotic site was removed and specimens were collected and sent for histopathologic and biochemical analysis (Figure 4). For histology, the specimens were preserved in formalin $10 \%$ and for biochemical analysis the specimens were placed at $-70^{\circ} \mathrm{C}$. The resulting paraffin-embedded sections of 3-5 $\mu \mathrm{m}$ underwent haematoxylin- eosin $(\mathrm{H} \& \mathrm{E})$ staining and were scored according to the scale used by Erlich and Hunt modified by Phillips (5).

Neoangiogenesis was scored using a 5-point scale (0: No angiogenesis present, 1: minimal, 2: few, 3: many, 4: maximum).

Statistical analysis. Data collection and analysis of the results was performed with adherence to data protection principles. Statistical analysis was performed using the SPSS software (SPSS 20, Chicago, 
Table I. Comparison of study outcomes between animals grouped according to the use of fibrin glue (irrespectively of the type of anastomosis performed).

\begin{tabular}{|c|c|c|c|c|c|}
\hline & \multicolumn{2}{|c|}{ No fibrin glue } & \multicolumn{2}{|c|}{ Fibrin glue } & \multirow[t]{2}{*}{$p$-Value } \\
\hline & $\mathrm{n}$ & $(\%)$ & $\mathrm{n}$ & $(\%)$ & \\
\hline Adhesions & & & & & 0.175 \\
\hline 1 & 5 & $(50)$ & 2 & $(20)$ & \\
\hline 2 & 5 & $(50)$ & 8 & (80) & \\
\hline Leak & & & & & N/A \\
\hline Yes & 0 & (0) & 0 & (0) & \\
\hline No & 10 & (100) & 10 & $(100)$ & \\
\hline Peritonitis & & & & & 0.500 \\
\hline Yes & 1 & (10) & 0 & $(0)$ & \\
\hline No & 9 & (90) & 10 & (100) & \\
\hline Hydroxyproline & & 746 & & 1307 & 0.064 \\
\hline (median) (range) & & $431-2,067$ & & $694-5,113$ & \\
\hline $\begin{array}{l}\text { Bursting pressure }(\mathrm{mm} \mathrm{Hg}) \\
\text { (median) (range) }\end{array}$ & & $\begin{array}{c}147 \\
(85-283)\end{array}$ & & $\begin{array}{c}170 \\
(124-270)\end{array}$ & 0.429 \\
\hline Neoangiogenesis & & & & & 0.011 \\
\hline 1 & 0 & $(0)$ & 1 & (10) & \\
\hline 2 & 5 & $(50)$ & 0 & 0 & \\
\hline 3 & 0 & $(0)$ & 5 & $(50)$ & \\
\hline 4 & 5 & $(50)$ & 4 & $(40)$ & \\
\hline
\end{tabular}

$p<0.05$ was considered significant.

IL, USA). Descriptive statistics are expressed as frequencies and percentages for categorical and as medians with range for continuous variables. To compare study outcomes between groups we used chisquare test, Fisher exact and the Mann-Whitney $U$-test (for analysing the relationship between categorical and continuous variables respectively). Statistical significance was set at $p$-value $<0.05$.

\section{Results}

A total of 20 animals were used. Table I presents the comparison between the control group and the FG group irrespectively of the type of anastomosis. There were no statistically significant differences between groups in regard to the number of adhesions, presence of peritonitis and the bursting pressure $(p=0.175, p=0.500$, and $p=0.429$ respectively).

The levels of hydroxyproline approached, but did not reach, significance between the 2 groups $(p=0.064)$ with the FG group having a higher level than the control group $(1,307$ vs. 746 respectively).

The level of angiogenesis between the 2 groups was statistically significantly different; $90 \%$ of animals in the FG group showed angiogenesis levels of 3 and 4 compared to $50 \%$ of animals in the control group $(p=0.011)$.

Table II presents the study outcomes only for the animals that had a complete anastomosis $(n=10)$. There were no statistically significant differences between the groups in regard
Table II. Comparison of study outcomes between animals grouped according to the use of fibrin glue (only for animals with a complete anastomosis).

\begin{tabular}{|c|c|c|c|c|c|}
\hline \multirow{2}{*}{$\begin{array}{l}\text { Complete } \\
\text { anastomosis }\end{array}$} & \multicolumn{2}{|c|}{ No fibrin glue } & \multicolumn{2}{|c|}{ Fibrin glue } & \multirow[t]{2}{*}{$p$-Value } \\
\hline & $\mathrm{n}$ & $(\%)$ & $\mathrm{n}$ & $(\%)$ & \\
\hline Adhesions & & & & & 0.500 \\
\hline 1 & 3 & (60) & 2 & (40) & \\
\hline 2 & 2 & $(40)$ & 3 & $(60)$ & \\
\hline Leak & & & & & N/A \\
\hline Yes & 0 & (0) & 0 & (0) & \\
\hline No & 5 & $(100)$ & 5 & $(100)$ & \\
\hline Peritonitis & & & & & N/A \\
\hline Yes & 0 & (0) & 0 & (0) & \\
\hline No & 5 & $(100)$ & 5 & $(100)$ & \\
\hline Hydroxyproline & & 752 & & 2050 & 0.158 \\
\hline (median) (range) & & $499-2,067$ & & $694-5,113$ & \\
\hline $\begin{array}{l}\text { Bursting pressure }(\mathrm{mm} \mathrm{Hg}) \\
\text { (median) (range) }\end{array}$ & & $\begin{array}{c}153 \\
(85-283)\end{array}$ & & $\begin{array}{c}160 \\
(124-270)\end{array}$ & 0.829 \\
\hline Neoangiogenesis & & & & & 0.019 \\
\hline 1 & 0 & (0) & 1 & (20) & \\
\hline 2 & 4 & (80) & 0 & 0 & \\
\hline 3 & 0 & (0) & 4 & (80) & \\
\hline 4 & 1 & (20) & 0 & $(0)$ & \\
\hline
\end{tabular}

$p<0.05$ was considered significant.

to the number of adhesions, hydroxyproline levels and bursting pressure ( $p=0.500, p=0.158$, and $p=0.829$ respectively). There were no animals with leaks or peritonitis in both groups.

The level of angiogenesis between the two groups was statistically significantly different; $80 \%$ of animals in the FG group showed angiogenesis levels 3 and 4, compared to $20 \%$ of animals in the control group ( $p=0.019)$.

Table III presents the study outcomes only for the animals that had incomplete anastomosis $(n=10)$. There were no statistically significant differences between the groups in regard to the number of adhesions, presence of peritonitis, hydroxyproline levels, bursting pressure and neoangiogenesis $(p=0.222, \quad p=0.500, \quad p=0.098, \quad p=0.261$ and $p=0.368$ respectively). There were no animals with leaks in both groups.

\section{Discussion}

Adhesions are formed during healing; hence they appear more or less after most intrabdominal procedures. Adhesions usually have a positive effect on the anastomotic healing process, because they appear to cover small defects of the suture line and offer more vascularity in hypoperfused areas of the anastomosis $(6,7)$.

We showed that FG promotes the formation of adhesions around the anastomosis on the $7^{\text {th }}$ post-operative day irrespectively of the type of anastomosis, but the results did 
Table III. Comparison outcomes between animals grouped according to the use of fibrin glue (only for animals with an incomplete anastomosis).

\begin{tabular}{|c|c|c|c|c|c|}
\hline \multirow{2}{*}{$\begin{array}{l}\text { Incomplete } \\
\text { anastomosis }\end{array}$} & \multicolumn{2}{|c|}{ No fibrin glue } & \multicolumn{2}{|c|}{ Fibrin glue } & \multirow[t]{2}{*}{$p$-Value } \\
\hline & $\mathrm{n}$ & $(\%)$ & $\mathrm{n}$ & $(\%)$ & \\
\hline Adhesions & & & & & 0.222 \\
\hline 1 & 2 & $(40)$ & 0 & $(0)$ & \\
\hline 2 & 3 & $(60)$ & 5 & $(100)$ & \\
\hline Leak & & & & & N/A \\
\hline Yes & 0 & (0) & 0 & $(0)$ & \\
\hline No & 5 & $(100)$ & 5 & $(100)$ & \\
\hline Peritonitis & & & & & 0.500 \\
\hline Yes & 1 & $(20)$ & 0 & $(0)$ & \\
\hline No & 4 & $(80)$ & 5 & $(100)$ & \\
\hline Hydroxyproline & & 870 & & 1200 & 0.098 \\
\hline (median) (range) & & $430-1,300$ & & $790-1,891$ & \\
\hline $\begin{array}{l}\text { Bursting pressure }(\mathrm{mm} \mathrm{Hg}) \\
\text { (median) (range) }\end{array}$ & & $\begin{array}{c}140 \\
(105-190)\end{array}$ & & $\begin{array}{c}180 \\
(130-220)\end{array}$ & 0.261 \\
\hline Neoangiogenesis & & & & & 0.368 \\
\hline 2 & 1 & $(20)$ & 0 & 0 & \\
\hline 3 & 0 & $(0)$ & 1 & $(20)$ & \\
\hline 4 & 4 & $(80)$ & 4 & $(80)$ & \\
\hline
\end{tabular}

$p<0.05$ was considered significant.

not reach statistical significance. Ozel et al. reported a higher rate of adhesions in the group of rats that received a fibrin sealant compared to the control group (8).

Anastomotic leak is one of the most important indicators of the healing of the anastomosis. Early leak is a sign of intraoperative technical failure and it usually happens between the $7^{\text {th }}$ to $8^{\text {th }}$ post-operative day (9-12). In our study there was no difference in the leak rates between the diagnostic groups.

Bursting pressure is a reliable index for identifying the grade of strength and integrity of the anastomosis. We used the Laplace equation to measure the resistance of the bowel wall as the intraluminal pressure gradually increases $(13,14)$. Van der Vijver et al. also studied small bowel anastomosis and found that the bursting pressure was lower in the group that used a type of FG (3). However, in our study, bursting pressure was higher, but not statistically significantly different, in all FG groups compared to the control group. Furthermore, it seems that even if there is an anastomotic defect (translated as an intraoperative technical error), the use of FG can strengthen the anastomosis.

Neoangiogenesis can be an important parameter of anastomotic healing as it increases vascularity and promotes new tissue formation (15-18). In our study, the FG groups showed significant neoangiogenesis compared to control groups. That could potentially mean that during the first seven post-operative days, FG plays an important role in neoangiogenesis and therefore in anastomotic healing.
The value of our study lies in investigating the usefulness of FG in small bowel anastomosis. Future studies could use a higher number of animals to further consolidate our results and determine the time course of the histopathologic changes postoperatively.

\section{Conclusion}

In conclusion, FG seems to have a positive effect on ileoileal anastomoses. However, it is not entirely clear if this effect is due to mechanical support or to facilitation of the healing process. The above results are in agreement with a recent review by Nordentoft et al. who reported that FG does not have a consistent positive influence on the healing of gastrointestinal anastomoses (19). Further research is needed to determine the exact effect of FG on small bowel anastomosis with an aim to use it as an intraoperative adjunct during bowel resections in humans.

\section{Conflicts of Interest}

The Authors have no conflicts of interest in relation to this study.

\section{Authors' Contributions}

Ioannis Gerogiannis designed the study, performed the laboratory experiments and wrote the manuscript, Apostolos Papalois provided the scholarship via ELPEN Center and supervised the laboratory experiments, Dimitra Psalla supervised the statistical analysis and the interpretation of the results, and Apostolos Kambaroudis was the supervisor.

\section{Acknowledgements}

The Authors thank ELPEN Experimental - Research Center for the scholarship that they offered in order for this experimental study to be completed. Ioannis Gerogiannis was the recipient of the scholarship.

\section{References}

1 Saha AK, Tapping CR, Foley GT, Baker RP, Sagar PM, Burke DA, Sue-Ling HM and Finan PJ: Morbidity and mortality after closure of loop ileostomy. Colorectal Dis 11(8): 866-871, 2009. PMID: 19175627. DOI: 10.1111/j.1463-1318.2008.01708.x

2 Nordentoft T: Sealing of gastrointestinal anastomoses with fibrin glue coated collagen patch. Dan Med J 62(5): B5081, 2015. PMID: 26050838.

3 van der Vijver RJ, van Laarhoven CJ, de Man BM, Lomme RM and Hendriks T: The effect of fibrin glue on the early healing phase of intestinal anastomoses in the rat. Int J Colorectal Dis 27(8): 11011107, 2012. PMID: 22398458. DOI: 10.1007/s00384-012-1435-5

4 van der Ham AC, Kort WJ, Weijma IM, van den Ingh HF and Jeekel $\mathrm{H}$ : Healing of ischemic colonic anastomosis: fibrin sealant does not improve wound healing. Dis Colon Rectum 35(9): 884891, 1992. PMID: 1511651. DOI: 10.1007/BF02047878 
5 Ehrlich HP, Tarver $\mathrm{H}$ and Hunt TK: Effects of vitamin A and glucocorticoids upon inflammation and collagen synthesis. Ann Surg 177(2): 222-227, 1973. PMID: 4572787. DOI: 10.1097/ 00000658-197302000-00017

6 Kanellos I, Odisseos C, Zaraboukas T, Kavouni A, Galovatsea $\mathrm{K}$ and Dadoukis I: Colonic healing after early intraperitoneal administration of 5-fluorouracil and interferon in rats. Int $\mathrm{J}$ Colorectal Dis 12(1): 45-48, 1997. PMID: 9112151. DOI: $10.1007 / \mathrm{s} 003840050078$

7 Kanellos I, Kavouni A, Zaraboukas T, Odisseos C, Galovatsea $\mathrm{K}$ and Dadoukis I: Influence of intraperitoneal 5-fluorouracil plus folinic acid on the healing of colonic anastomoses in rats. Eur Surg Res 28(5): 374-379, 1996. PMID: 8880127. DOI: $10.1159 / 000129479$

8 Ozel SK, Kazez A and Akpolat N: Does a fibrin-collagen patch support early anastomotic healing in the colon? An experimental study. Tech Coloproctol 10(3): 233-236, 2006. PMID: 16969611. DOI: $10.1007 / \mathrm{s} 10151-006-0285-\mathrm{y}$

9 Zacharakis E, Demetriades H, Kanellos D, Sapidis N, Zacharakis E, Mantzoros I, Kanellos I, Koliakos G, Zaraboukas T, Topouridou $\mathrm{K}$ and Betsis D: Contribution of insulin-like growth factor I to the healing of colonic anastomoses in rats. J Invest Surg 20(1): 9-14, 2007. PMID: 17365402 . DOI: 10.1080/08941930601126074

10 Kanellos I, Vasiliadis K, Angelopoulos S, Tsachalis T, Pramateftakis MG, Mantzoros I and Betsis D: Anastomotic leakage following anterior resection for rectal cancer. Tech Coloproctol 8 Suppl 1: s79-s81, 2004. PMID: 15655652. DOI: 10.1007/s10151-004-0119-8

11 Villar JM, Martinez AP, Villegas MT, Muffak K, Mansilla A, Garrote D and Ferron JA: Surgical options for malignant leftsided colonic obstruction. Surg Today 35(4): 275-281, 2005. PMID: 15815842. DOI: 10.1007/s00595-004-2931-1

12 El-Malt M, Ceelen W, Boterberg T, Claeys G, de Hemptinne B, de Neve W and Pattyn P: Does the addition of glutamine to total parenteral nutrition have beneficial effect on the healing of colon anastomosis and bacterial translocation after preoperative radiotherapy? Am J Clin Oncol 26(3): e54-e59, 2003. PMID: 12796616. DOI: 10.1097/01.COC.0000072505.67810.B1
13 Kanellos I, Mantzoros I, Demetriades H, Kalfadis S, Kelpis T, Sakkas L and Betsis D: Healing of colon anastomoses covered with fibrin glue after immediate postoperative intraperitoneal administration of 5-fluorouracil. Dis Colon Rectum 47(4): 510515, 2004. PMID: 14978614. DOI: 10.1007/s10350-003-0085-7

14 Cihan A, Armutcu F, Uçan BH, Acun Z, Numanoglu VK, Gürel A and Ulukent SC: Comparison of the measurement methods of bursting pressure of intestinal anastomoses. Hepatogastroenterology 50(Suppl 2): ccxxxii-ccxxxiv, 2003. PMID: 15244188.

15 Distler JH, Hirth A, Kurowska-Stolarska M, Gay RE, Gay S and Distler O: Angiogenic and angiostatic factors in the molecular control of angiogenesis. Q J Nucl Med 47(3): 149-161, 2003. PMID: 12897707.

16 McNamara DA, Harmey JH, Walsh TN, Redmond HP and Bouchier-Hayes DJ: Significance of angiogenesis in cancer therapy. Br J Surg 85(8): 1044-1055, 1998. PMID: 9717994. DOI: $10.1046 / j .1365-2168.1998 .00816 . x$

17 Risau W: Mechanisms of angiogenesis. Nature 386(6626): 671674, 1997. PMID: 9109485. DOI: 10.1038/386671a0

18 van der Bilt JD and Borel Rinkes IH: Surgery and angiogenesis. Biochim Biophys Acta 1654(1): 95-104, 2004. PMID: 14984770. DOI: 10.1016/j.bbcan.2004.01.003

19 Nordentoft T, Pommergaard HC, Rosenberg J and Achiam MP: Fibrin glue does not improve healing of gastrointestinal anastomoses: a systematic review. Eur Surg Res 54(1-2): 1-13, 2015. PMID: 25247310. DOI: $10.1159 / 000366418$

Received November 13, 2021

Revised November 29, 2021

Accepted November 30, 2021 